воздействия продуктов диссоциации воды на процесс сгорания. По результатам исследований сделаны выводы о степени влияния каждого из механизмов в течении отдельных периодов сгорания.

\title{
FEATURES COMBUSTION PROCESS IN DIESEL ENGINES WHEN WORKING AT WATER-FUEL EMULSION
}

\section{A.P. Marchenko, I.V. Parsadanov, A.A. Prokhorenko, A.V. Savchenko, A.A. Osetrov, D.V. Meshkov}

Analyzed the physical-chemical properties of water-fuel emulsion and their effect on mixture formation and combustion of fuel. Method of holding and results of experimental research of diesel engine 4CHN12 / 14 on water-fuel emulsion. Analyzed the main hypothesis, revealing the effect mechanism of water emulsion fuel mixture formation and combustion processes: hypothesis of "micro-explosions" hypothesis and catalytic effects of products of dissociation of water in the combustion process. According to the research findings on the extent of the influence of each of the mechanisms within individual periods.

\section{Р. Н. Радченко, Н. С. Богданов}

\section{ЭФФЕКТИВНОСТЬ ТРАНСФОРМАЦИИ ТЕПЛОТЫ В ТРЕХСТУПЕНЧАТОЙ СИСТЕМЕ ОХЛАЖДЕНИЯ НАДДУВОЧНОГО ВОЗДУХА СУДОВОГО МАЛООБОРОТНОГО ДИЗЕЛЯ}

\begin{abstract}
Проанализирована эффективность трансформачии теплоты в трехступенчатой системе охлаждения наддувочного воздуха судового малооборотного дизеля. Трехступенчатый охладитель наддувочного воздуха такой системы включает последовательно расположенные в воздушном тракте высокотемпературную ступень отвода высокопотенциальной теплоты от наддувочного воздуха после турбокомпрессора на нагрев промежуточного теплоносителя, служащего источником теплоты для теплоиспользующей холодильной машины, ступень охлаждения наддувочного воздуха забортной водой и низкотемпературную ступень глубокого охлаждения наддувочного воздуха, использующую холод, генерируемый теплоиспользующей холодильной машиной.
\end{abstract}

\section{Анализ проблемы и постановка цели исследования}

На судах морского флота в качестве главных двигателей применяются в основном малооборотные дизели (МОД). Их термодинамическая эффективность зависит в значительной степени от температуры наддувочного воздуха: с eе повышением эффективный КПД МОД снижается, а удельный расход топлива $b_{e}$, соответственно, возрастает [1-3].

В судовых МОД все более широкое распространение находят двухступенчатые системы охлаждения наддувочного воздуха с использованием теплоты, отводимой в высокотемпературной ступени охладителя наддувочного воздуха $\left(\mathrm{OHB}_{\mathrm{BT}}\right)$, для нагрева воды на нужды судовой энергетической установки, например, нагрева питательной воды утилизационного пароводяного котла (УК) до температуры примерно $90^{\circ} \mathrm{C}$, нагрева топлива, масла, на другие теплофикационные цели.

Однако, опыт эксплуатации МОД транспортных судов показывает, что при нагрузках главного двигателя свыше 50 \% генерируемая теплота превышает потребности судовых потребителей, а при нагрузках главного двигателя $85 \ldots 90$ \% и температуре наружного воздуха около $0{ }^{\circ} \mathrm{C}$ это превышение составляет $50 \ldots 100 \%$, что резко снижает эф- фективность утилизации теплоты [3]. В то же время повышенные температуры забортной воды в системе охлаждения наддувочного воздуха приводят к падению эффективных КПД и мощности, возрастанию удельного расхода топлива $b_{e}$, что весьма остро ставит проблему охлаждения наддувочного воздуха. Одним из направлений ее решения является применение теплоиспользующих холодильных машин (ТХМ), утилизирующих теплоту наддувочного воздуха, выпускных газов и других источников сбросной теплоты МОД [4-6].

Цель работы - анализ эффективности трансформации теплоты в трехступенчатой системе охлаждения наддувочного воздуха судового МОД.

\section{Изложения основного материала}

Наиболее простой и надежной в эксплуатации из теплоиспользующих холодильных машин является эжекторная холодильная машина (ЭХМ). Использование в ЭХМ низкокипящего рабочего тела (НРТ)-хладагента обеспечивает глубокое охлаждение воздуха без поддержания вакуума в испарителе НРТ-охладителе воды (И-ОВ) промежуточного водяного контура охлаждения наддувочного воздуха.

На рис. 1 приведена схема трехступенчатой системы охлаждения наддувочного воздуха на базе ЭХМ, использующей теплоту наддувочного воздуха. Теплоиспользующая система охлаждения (ТСО) 
наддувочного воздуха на базе ЭХМ включает последовательно расположенные в воздушном тракте высокотемпературную ступень охлаждения $\mathrm{OHB}_{\mathrm{BT}}$ (после ТК), промежуточную ступень охлаждения (ПО) наддувочного воздуха забортной водой и низкотемпературную ступень $\mathrm{OHB}_{\mathrm{HT}}$ дополнительного глубокого охлаждения воздуха в ЭХМ после его охлаждения забортной водой в ПО. Теплота, отведенная от воздуха в $\mathrm{OHB}_{\mathrm{BT}}$, трансформируется с помощью ЭХМ в холод, используемый для охлаждения воздуха в $\mathrm{OHB}_{\mathrm{HT}}$.

Генератор ЭХМ состоит из двух секций: экономайзерной $\Gamma_{э}$, в которой происходит нагрев жидкого НРТ, поступающего из конденсатора ЭХМ с температурой конденсации, например $t_{\mathrm{\kappa}}=35 \ldots 45^{\circ} \mathrm{C}$, до температуры кипения НРТ в испарительной секции $\Gamma_{\text {и }}$ генератора $t_{\mathrm{\Gamma}}=100 \ldots 120^{\circ} \mathrm{C}$ промежуточным теплоносителем-пресной водой, к которой, в свою очередь, подводится теплота $Q_{\text {г }}$ от наддувочного воздуха после ТК в $\mathrm{OHB}_{\mathrm{BT}}$, в результате чего температура наддувочного воздуха снижается от $t_{\mathrm{B}}=t_{\mathrm{r} 1}=230 \ldots 240^{\circ} \mathrm{C}$ (на входе $\mathrm{OHB}_{\mathrm{BT}}$ ) до $t_{\mathrm{B}}=t_{\mathrm{r} 2}=110{ }^{\circ} \mathrm{C}$ (на выходе из $\mathrm{OHB}_{\mathrm{BT}}-$ входе в ПО).

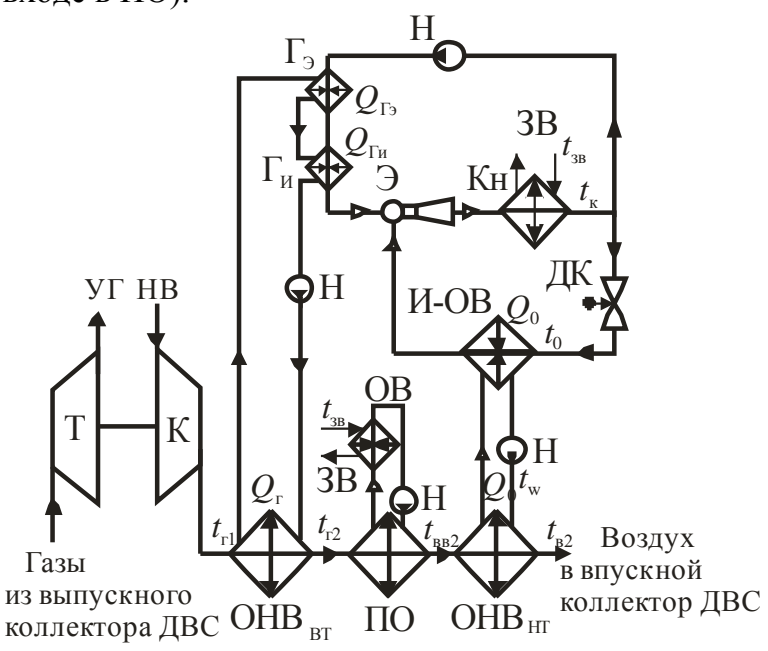

Рис. 1. Схема трехступенчатой системы охлаждения наддувочного воздуха на базе ЭХМ, использующей теплоту наддувочного воздуха: $K u T-$ компрессор и турбина ТК ДВС; ОНВ высоко- и низкотемпературная ступени ОНВ; ПО - промежуточный охладитель наддувочного воздуха (забортной водой); ЭХМ: Гэ и $\Gamma_{И}-$ экономайзерная и испарительная секции генератора ЭХМ; Кн-конденсатор; И-ОВ - испаритель-охладитель пресной воды; H-насос; ДК - дроссельный клапан; НВ -наружный воздух; УГ-уходящие газы ДВС; ЗВ - забортная вода

Из генератора пары НРТ поступают в конденсатор ЭХМ, охлаждаемый забортной водой, и конденсируются, а жидкий НРТ после дросселирования испаряется в испарителе- охладителе воды (И-ОВ) при низком давлении, соответственно и температуре $t_{0}=3 \ldots 5^{\circ} \mathrm{C}$, охлаждая воду, в свою очередь отводящую теплоту $Q_{0}$ от наддувочного воздуха в $\mathrm{OHB}_{\mathrm{HT}}$.

Такая ТСО представляет собой трехступенчатую трехконтурную систему охлаждения наддувочного воздуха с пресной водой - в первом, НРТ во втором и забортной водой - в третьем, разомкнутом, контурах охлаждения. Она обеспечивает охлаждение наддувочного воздуха ниже температуры забортной воды.

При этом теплота, отведенная от наддувочно-

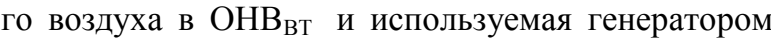
ЭХМ: $Q_{\Gamma}=G_{\mathrm{B}} \cdot c_{\mathrm{B}}\left(t_{\Gamma 1}-t_{\text {г2 }}\right)$, где $G_{\mathrm{B}}-$ расход воздуха; $c_{\mathrm{B}}-$ теплоемкость воздуха; $t_{\text {г1 }}$ и $t_{\text {г2 }}-$ температуры наддувочного воздуха (греющей среды для ЭХМ) на входе и выходе ОНВ $_{\text {Вт, }}$ соответственно; температуры забортной воды $t_{3 в}$ и пресной воды $t_{w}$ промежуточного контура охлаждения, наддувочного воздуха $t_{\text {вв2 }}$, охлажденного в ПО (на входе в $\mathrm{OHB}_{\mathrm{HT}}$ ) и наддувочного воздуха $t_{\mathrm{в} 2}$, охлажденного в $\mathrm{OHB}_{\mathrm{HT}}$; кипения хладона $t_{0}$ в испарителеохладителе пресной воды (И-ОВ).

Эффективность трансформации теплоты в системе охлаждения наддувочного воздуха судового МОД с помощью ЭХМ характеризуется тепловым коэффициентом $\zeta=Q_{0} / Q_{\text {г }}$, представляющим собой отношение полученной холодопроизводительности $Q_{0}$ к затраченной теплоте $Q_{\text {г }}$.

На рис. 2 приведено изменение температуры воздуха $t_{\mathrm{B}}$, пресной воды $t_{\mathrm{w}}$ и хладагента $t_{0}$ в генераторе и испарителе НРТ (И-ОВ), а также коэффициентов теплоотдачи к воде $\alpha_{w}$, воздуху $\alpha_{\text {в }}$, хладагенту $\alpha_{a}$ и теплопередачи $k$, приведенных к внутренней поверхности труб, температурного напора $\theta$, плотности теплового потока $q$ к внутренней поверхности труб и тепловой нагрузки Q по глубине $L$ трехступенчатого ОНВ (по ходу воздуха) при температуре воздуха на выходе $\mathrm{OHB}_{\mathrm{BT}}$ - его экономайзерной секции $t_{\mathrm{B}}=t_{\mathrm{r} 2}=110^{\circ} \mathrm{C}$.

Потенциально возможная минимальная температура охлажденного воздуха $t_{\text {в2 }}$ на выходе из $\mathrm{OHB}_{\mathrm{HT}}$ зависит от температуры кипения НРТ $t_{0}$ : $t_{\mathrm{B} 2}=t_{0}+5^{\circ} \mathrm{C}+12{ }^{\circ} \mathrm{C}$, где $5^{\circ} \mathrm{C}$ - разница температур пресной воды и НРТ (хладагента) в И-ОВ, а $12{ }^{\circ} \mathrm{C}$ - разница температур наддувочного воздуха и пресной воды промежуточного водяного контура охлаждения в $\mathrm{OHB}_{\mathrm{HT}}$.

Результаты расчетов показали, что при охлаждении наддувочного воздуха после ТК в ОНВ температуры $t_{\mathrm{B}}=\mathrm{t}_{\mathrm{r} 2}=110^{\circ} \mathrm{C}$ температура наддувочного воздуха после $\mathrm{OHB}_{\mathrm{HT}}$ составляет примерно $t_{\mathrm{B} 2}=22^{\circ} \mathrm{C}$, т.е. практически равна потенциально возможной минимальной ее величине при температуре кипения НРТ $t_{0}=5{ }^{\circ} \mathrm{C}$. 


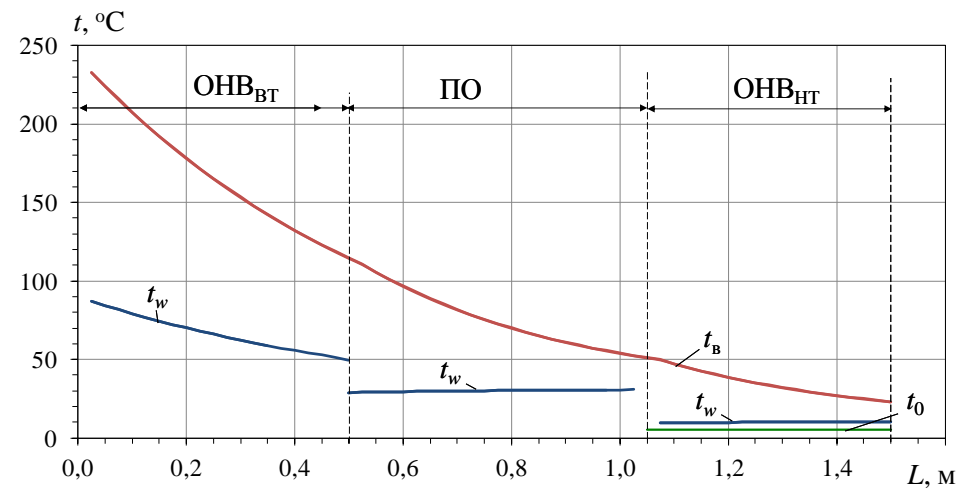

a)

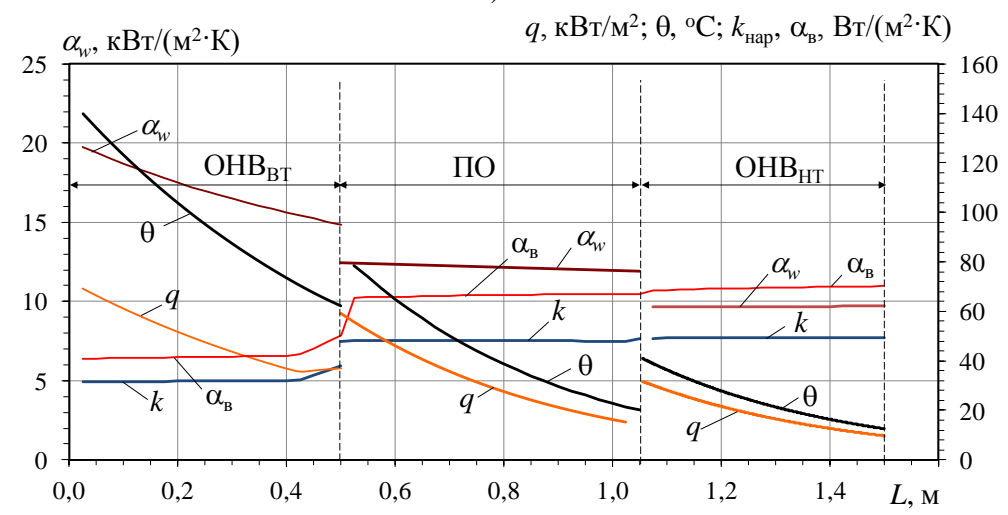

б)

Рис. 2. Изменение температуры наддувочного воздуха $t_{6}$, пресной воды $t_{w}$ промежуточного контура охлаждения (воздух-вода) и НРТ в генераторе $t_{2}$ и испарителе $t_{0}$ ТЭХМ (a), а также коэффициентов теплоот-

дачи к воде $\alpha_{w}$, воздуху $\alpha_{b}$, хладагенту $\alpha_{a}$ и теплопередачи $k$, приведенных к внутренней поверхности труб, температурного напора $\theta$, плотности теплового потока q к внутренней поверхности труб и тепловой нагрузки $Q$ (б) по глубине L (по ходу воздуха) трехступенчатого ОНВ при температуре наддувочного воздуха на выходе из $О \mathrm{OB}_{B T} t_{6}=t_{22}=110^{\circ} \mathrm{C}$

Изменение тепловой нагрузки Q, влагосодержания d, коэффициента влаговыпадения $\xi$, количества влаги $\mathrm{W}$, выпадающей из воздуха, и аэродина- мического сопротивления $\Delta \mathrm{P}$ по глубине $L$ трехступенчатого ОНВ по воздуху $\left(t_{0}=5{ }^{\circ} \mathrm{C} ; t_{\mathrm{B}}=t_{\mathrm{r} 2}=\right.$ $\left.110^{\circ} \mathrm{C}\right)$ приведено на рис. 3 .

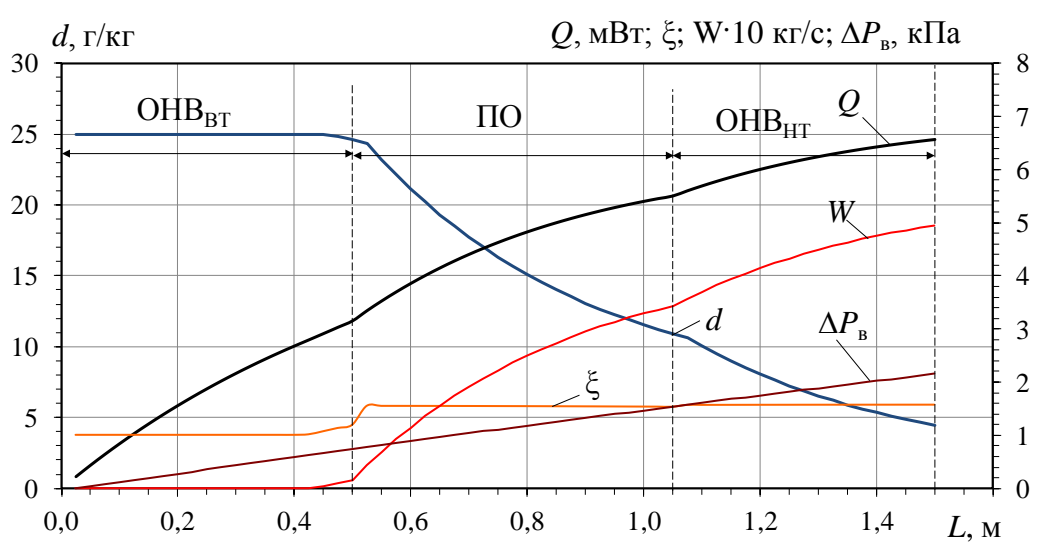

Pис. 3. Изменение тепловой нагрузки $Q$, влагосодержания $d$, коэффициента влаговыпадения $\xi$, количества влаги $W$, выпадающей из воздуха, и аэродинамического сопротивления $\triangle P$ по глубине L трехступенчатого OHВ по воздуху $\left(t_{0}=5^{\circ} \mathrm{C} ; t_{6}=t_{22}=110^{\circ} \mathrm{C}\right)$

При этом глубина трехступенчатого ОНВ по ходу воздуха $L=1,5$ м, аэродинамическое сопротивление $\Delta P=2200$ Па.
Зависимость теплового коэффициента $\zeta$ трансформации теплоты наддувочного воздуха от его температуры на выходе из $\mathrm{OHB}_{\mathrm{BT}} t_{\mathrm{B}}=t_{\text {г2 }}$ при 
охлаждении воздуха в $\mathrm{OHB}_{\mathrm{HT}}$ до $t_{\mathrm{B} 2}=22{ }^{\circ} \mathrm{C}$ показана на рис. 4.

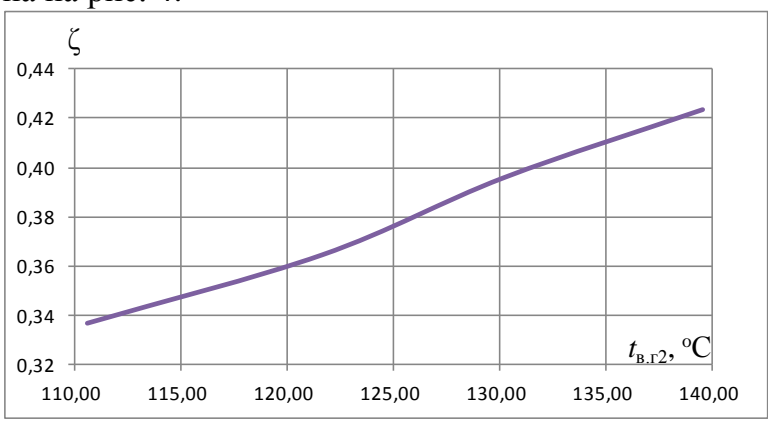

Рис. 4. Зависимость теплового коэффициента Ц трансформации теплоты наддувочного воздуха от его температуры на выходе из $\mathrm{OHB}_{B T} t_{22}$ nри охлаждении воздуха в $О \mathrm{OH}_{H T}$ до $t_{62}=22{ }^{\circ} \mathrm{C}$

Как видно, для охлаждения наддувочного воздуха в $\mathrm{OHB}_{\text {Hт }}$ до минимальной температуры, потенциально возможной при температуре кипения НРТ $t_{0}=5{ }^{\circ} \mathrm{C}$ и воздуха на входе ОНВ $t_{\mathrm{B}}=t_{\Gamma 1}=230 \ldots 240^{\circ} \mathrm{C}$ теплоты, отведенной от воздуха в $\mathrm{OHB}_{\mathrm{BT}}$ при снижении его температуры до $t_{\mathrm{B}}=t_{\mathrm{\Gamma} 2}=110^{\circ} \mathrm{C}$, будет достаточно, если $\zeta \geq 0,34$.

\section{Заключение}

В результате анализа эффективности трансформации теплоты в трехступенчатой системе охлаждения наддувочного воздуха судового МОД определены минимальные значения теплового коэффициента $\zeta$ теплоиспользующей холодильной машины, обеспечивающие максимальную глубину охлаждения за счет высокопотенциальной теплоты, отводимой от наддувочного воздуха после ТК.

\section{Список литературы:}

1. Influence of Ambient Temperature Conditions. Main engine operation of MAN B\&W two-stroke engines [Text] // MAN Diesel \& Turbo. - Copenhagen, Denmark, 2010. 17 p. 2. Thermo Efficiency System (TES) for reduction of fuel consumption and $\mathrm{CO}_{2}$ emission [Electronic resource] // MAN $B \& W$ Diesel A/S. - Copenhagen, Denmark, 2005. - 15 p. Access mode: http://marine.man.eu/docs/librariesprovider6/ technical- papers/thermo-efficiency-system.pdf?sfvrsn=22. 3 . $M A N$ B\&W ME/ME-C/ME-GI/ME-B-TII engines [Electronic resource]. - Copenhagen, Denmark : MAN Diesel. - 2010. $357 \mathrm{p}$. - Access mode: http://www.mandieselturbo.com /download/project_guides_tier2/printed/s90mcc8.pdf. 4. Радченко, Р.Н. Основы рационального проектирования системы охлаждения наддувочного воздуха судового малооборотного дизеля эжекторным термотрансформатором [Текст]/ Р.Н. Радченко, Н.С. Богданов, И.В. Калиниченко //Авиационно-космическая техника и технология. - 2015. - № 5(122). - С. 65-68.

\section{Bibliography (transliterated):}

1. Influence of Ambient Temperature Conditions. Main engine operation of MAN B\&W two-stroke engines (2010), MAN Diesel \& Turbo, Copenhagen, Denmark, 17 p. 2. Thermo Efficiency System (TES) for reduction of fuel consumption and $\mathrm{CO}_{2}$ emission (2005), MAN B\&W Diesel A/S, Copenhagen, Denmark, 15 p. - Access mode: http://marine.man.eu/docs/librariesprovider6/ technical- papers/thermo-efficiency-system.pdf?sfvrsn $=22 . \quad 3 . \quad M A N \quad B \& W$ ME/ME-C/ME-GI/ME-B-TII engines (2010), Copenhagen, Denmark: MAN Diesel. $357 \mathrm{p}$. - Access mode: http://www.mandieselturbo.com/download/project_guides_tier2/prin ted/s90mcc8.pdf. 4. Radchenko, R.N., Bogdanov N.S., Kalinichenko I.V. (2015), "Rational designing of marine low speed diesel scavenge air cooling system with ejector thermotransformers", Aerospace Technic and Technology ["Osnovy racionalnogo proektirovaniya sistemy ohlazhdeniya naddyvochnogo vozduha sudovogo malooborotnogo dizelya ezhektornymi termotransformatorami", Aviacionno-kosmicheskaja tehnika i tehnologija], № 5/122, pp. 65-68

Поступила в редакичию 07.06.2016 2.

Радченко Роман Николаевич - канд. техн. наук, ст. науч. сотр. кафедры кондиционирования и рефрижерации Национального университета кораблестроения им. адмирала Макарова, Николаев, Украина, e-mail: andrad69@mail.ru.

Богданов Николай Семенович - аспирант Национального университета "Одесская морская академия".

\section{ЕФЕКТИВНІСТЬ ТРАНСФОРМАЦІЇ ТЕПЛОТИ В ТРИСТУПІНЧАСТІЙ СИСТЕМІ ОХОЛОДЖЕННЯ НАДДУВНОГО ПОВІТРЯ СУДНОВОГО МАЛООБЕРТОВОГО ДИЗЕЛЯ}

\section{Р. М. Радченко, М. С. Богданов}

Проаналізована ефективність трансформації теплоти в триступінчастій системі охолодження наддувного повітря суднового малообертового дизеля. Триступінчастий охолоджувач наддувного повітря такої системи включає послідовно розташовані у повітряному тракті високотемпературний ступінь відводу високопотенційної теплоти от наддувного повітря після турбокомпресора на нагрів проміжного теплоносія, який служить джерелом теплоти для тепловикористовуючої холодильної машини, ступінь охолодження наддувного повітря забортною водою та низькотемпературний ступінь глибокого охолодження наддувного повітря, що використовує холод, генерований тепловикористовуючою холодильною машиною.

\section{THE EFFICIENCY OF HEAT TRANSFORMATION IN THREE-STAGE SCAVENGE AIR COOLING SYSTEM OF MARINE LOW SPEED DIESEL ENGINE}

\section{R. M. Radchenko, N. S. Bohdanov}

Transformation efficiency of heat in the three-stage charge air cooling system of marine diesel engine was investigated. A three stage air cooler of this system includes consistently located inside tract with high temperature heat from high-grade dissipation stage supercharging air after turbocharger for heating an intermediate coolant, the heat source for the employee by waste heat recovery refrigeration machine, step charging air cooling seawater and low-temperature stage of deep cooling charge air cooler that uses cold, generated by waste heat recovery refrigeration machine. 